\title{
O Cientista como Observador e Actor
}

\author{
A. M. NUNES DOS SANTOS*
}

What we don't understand we explain to each other.

Robert J. Oppenheimer (1904-1967)

... There is a tendency to forget that all science is bound up with human culture in general, and that scientific findings, even those which at the moment appear the most advanced and esoteric and difficult to grasp are meaningless outside their culture context.

Erwin Schrödinger (1887-1961)

No man should escape our universities without... some sense of the fact that not through his fault, but in the nature of things, he is going to be an ignorant man, and so is everyone else.

Oppenheimer, Science Values and the Human Community

Em 23 de Novembro de 1952, Enrico Fermi publicava um artigo no jornal Chicago Sun-Times, um artigo comemorativo do décimo aniversário da realização da primeira reacção nuclear em cadeia controlada, um acontecimento que teve lugar debaixo da bancada ocidental do Estádio Stagg Field em Chicago, próximo da Universidade, e que a maior parte das pessoas associa ao desenvolvimento da bomba atómica e aos esforços subsequentes da construção da bomba de hidrogénio. Nesse artigo, Fermi afirmava o seguinte: "A história da primeira reacção nuclear em cadeia sob controlo, tal como qualquer acontecimento científico, começa com as primeiras especulações filosóficas do homem sobre a natureza do universo. As suas últimas consequências são sempre imprevisíveis. A sequência das descobertas conducente à reacção nuclear em cadeia faz parte da busca da ciência para uma melhor explicação da natureza e do mundo que nos rodeia. No início, ninguém tinha qualquer ideia ou intenção de contribuir para um de- senvolvimento crucial quer industrial quer militar".

E hoje, volvidos mais de sessenta anos, apesar de se conhecerem as consequências das aplicações das reacções nucleares, persiste o desafio intelectual para a aquisição do "novo" conhecimento provisório que anima o recontar das estórias, como se a missão da busca do aprofundamento e compreensão da natureza constituísse o único alvo do cientista. Foi assim que o senti, quando, em Dezembro de 1992, precisamente no dia dois, na reunião Comemorativa intitulada Nuclear Chain Reaction 50th Anniversary (An International Meeting at the Science Museum), numa audiência de 150 pessoas, ouvi Sir Rudolf Peierls (um dos físicos teóricos que, em 1940, em colaboração com Otto Frisch, foi autor do célebre memorandum que inclui o cálculo da quantidade de $U^{235}$ necessária à produção da reacção nuclear em cadeia), e Harold Agnew e Warren Nyer, dois investigadores americanos que assistiram à reacção realizada em $1942^{1}$. Animados, reviviam os momen- tos em que abraçaram o início de uma era - a do nuclear - um passo crucial que teria profundas consequências para o estatuto da ciência: tida até então como o habitat da vida e do bem-estar das Nações, a ciência passava em breve a ser igualmente o habitat da morte. Era o momento em que a ciência maculava a sua inocência, ainda na forma de pressentimento que se tornaria realidade anos mais tarde; uma mácula tão lesiva que ainda hoje no imaginário contemporâneo, o nuclear é uma das metáforas simbólicas do Mal. É curioso que, após o sucesso de realização da experiência, nessa manhã de 2 de Dezembro de 1942, na culminação de um trabalho árduo e contínuo (os cientistas trabalhavam 18 h diárias) não houvesse discursos, nem vozes vibrantes e excitadas, nem fotografias; apenas um silêncio, um enorme silêncio não quebrado pelos brindes feitos com copos de papel contendo um Chianti que Eugene Wigner havia adquirido alguns meses antes para esta ocasião de modo a homenagear Fermi. Inconscientemente, a maioria pensava sobre as implicações da ex-

\footnotetext{
*Faculdade de Ciências e Tecnologia (FCT), Universidade Nova de Lisboa (amns@fct.unl.pt)
} 
periência acabada de realizar, mas tal não era suficiente para atenuar o ânimo interior de muitos que nela participaram. Assim, quando Warren Nyer toma a palavra na referida reunião, relata-nos: "Contudo, eu pressentia, à idade de 23 anos, que os próximos 3 a 4 anos (na realidade até Agosto de 1945) seriam pontos culminantes da minha vida, em termos de impulso e estímulo intelectual, já que teria o privilégio de participar num acontecimento único e grandioso". E é muitas vezes este entusiasmo natural, este desafio intelectual que alicia os jovens investigadores para a necessidade de uma maior aprendizagem, que acalenta a curiosidade do homem, a sua compreensão para assimilar o que é novo, difícil e profundo, que Ihe revela a beleza de uma nova estrutura lógica, e que o leva a partilhar o conhecimento, a comunicá-lo e a ser solidário numa grande aventura, algo profundamente inspirador.

Aqui temos o cientista na pele de observador nato: o seu interagir reflecte um olhar intenso, profundo e controlado um verdadeiro perscrutador da natureza. Fá-lo, por vezes, por motivos inabaláveis e incontroláveis. Não se pode ser cientista se não acreditarmos na aprendizagem e na partilha do conhecimento. O secretismo colide com e corrompe a raiz mais profunda do que é a ciência. $A$ permuta de informação deve ser aber$t^{2}{ }^{2}$. Que razões levaram então uma comunidade a agir, a adaptar-se sem visível relutância a um secretismo que abala o espírito de irmandade ${ }^{3}$ o qual considera o conhecimento como valor intrínseco da humanidade, que, consequentemente deve ser sempre difundido? Aparentemente poder-se-ia pensar que tal secretismo era uma imposição exterior, já que o grande empreendimento - o Projecto Manhattan - que conduziu ao fabrico da bomba atómica, estava sob alçada militar. Contudo, os factos são diferentes. Quando Otto Hahn e Fritz Strassmann publicaram, em 1939, o artigo no Naturwissenschaften (vol 27, p. 11) em que indicavam ter encontrado bário radioactivo entre os produtos do bombardeamento do urânio pelos neutrões, um resultado que os tinha espantado ${ }^{4}$ mas que, do ponto de vista experimental não tinham outra alternativa senão acreditar nesse fenómeno - o fenómeno da cisão nuclear - muitos censuraram-nos por terem publicado o artigo na íntegra, tornando-o disponível aos olhos do mundo. Mais apreensivos ficaram alguns cientistas com a publicação da "Letter" de Frédéric Joliot na Nature, em 22 de Abril de 1939, em que se divulgava a hipótese da construção de bombas nucleares a partir do fenómeno da cisão, já que grandes quantidades de energia eram libertadas nesse fenómeno juntamente com a libertação de 3 ou 4 neutrões que provocariam reacções em cadeia.
A repercussão desta publicação foi enorme: uma semana depois da publicação, a 25 de Abril, a Alemanha decidia adquirir todo o stock de urânio disponível nas minas de Joachimsthal da Checoslováquia, recentemente anexada, e os russos ${ }^{5}$ através do físico Igor Tamm, tomaram consciência da importância deste fenómeno:

"Sabem o que significa esta descoberta? Significa que se pode construir uma bomba que destruirá uma cidade num raio de 10 quilómetros" - comentava tal físico a um grupo de estudantes.

Tabela 1 - Prémios Nobel exilados no período 1933-1940

\begin{tabular}{|c|c|c|c|}
\hline Prémio Nobel da Química & PN & Ano Saída & País Acolhedor \\
\hline Fritz Haber & 1918 & 1933 & m.1934 \\
\hline Peter Debye & 1936 & 1940 & USA \\
\hline George de Hevesy & 1943 & 1934 & Suécia \\
\hline Gerhard Herzberg & 1971 & 1935 & Canadá \\
\hline Prémio Nobel da Física & PN & Ano Saída & País Acolhedor \\
\hline Albert Einstein & 1921 & 1933 & USA \\
\hline James Franck & 1925 & 1933 & USA \\
\hline Guslav Hertz & 1925 & 1935 & $\begin{array}{l}\text { Alemanha } \\
\text { Oriental }\end{array}$ \\
\hline Erwin Schrödinger & 1933 & 1938 & Irlanda \\
\hline Victor Hess & 1936 & 1933 & USA \\
\hline Otto Stern & 1943 & 1933 & USA \\
\hline Felix Bloch & 1952 & 1933 & USA \\
\hline Max Bom & 1954 & 1933 & UK \\
\hline Eugene Wigner & 1963 & 1933 & USA \\
\hline Hans Bethe & 1967 & 1933 & USA \\
\hline Dennis Gabor & 1971 & 1933 & UK \\
\hline Prémio Nobel da Fisiologia & PN & Ano Saída & País Acolhedor \\
\hline Otto Meyerhof & 1922 & 1938 & França, USA \\
\hline Otto Loewi & 1936 & 1938 & USA \\
\hline Boris Chain & 1945 & 1933 & UK \\
\hline Hans A. Krebs & 1953 & 1933 & UK \\
\hline Max Delbrück & 1969 & 1937 & USA \\
\hline
\end{tabular}




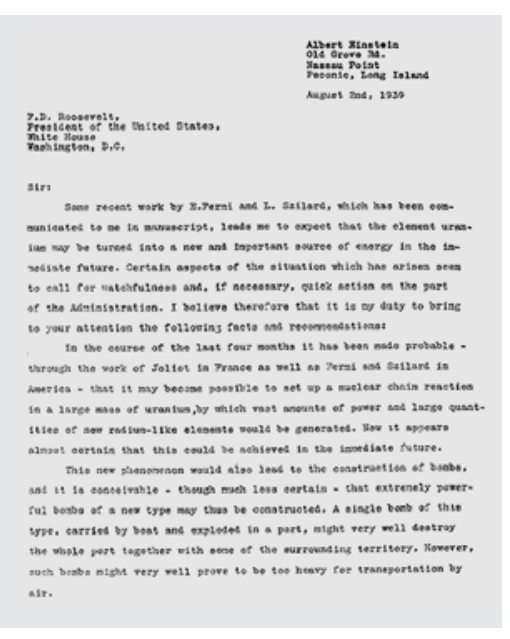

Conhecedores de alguns destes factos, nomeadamente do que se passava na Alemanha, os cientistas ficaram alarmados. A Alemanha era o verdadeiro inimigo e Hitler estava no auge do poder. Nunca, na história da humanidade, tinha havido tanto ressentimento pela perversão do poder político; nunca tinha havido antes uma depuração tão forte da intelligentsia, uma depuração baseada em preconceitos rácicos (não se pense que membros da comunidade científica escapavam a esse preconceito: veja-se, por exemplo, o caso de Philipps Lenard (1862-1947), Prémio Nobel da Física em 1905, que, nos quatro volumes intitulados Física Alemã, contrastava a física ariana e a judaica, afirmando: "A Ciência, como qualquer outro produto humano, é racial e condicionada pelo sangue") independente da contribuição dada pelo cientista e do seu valor. No período de 1933-1940 saíram da Alemanha centenas de cientistas entre os quais vinte (!) eram ou vieram a ser galardoados com o Prémio Nobel (Tabela 1).

Face a esta situação trágica, Leo Szilard e Edward Teller (dois dos cientistas conhecidos como Men from Mars, já que nesse período se notabilizaram 7 cientistas provenientes da Hungria: além dos mencionados, Theodor von Kármán, George de Hevesy, Michael Polanyi, Eugene Wigner e John von Neumann) pressionaram Einstein a escrever em 2 Agosto desse mesmo ano a célebre carta ao Presidente Roosevelt (que chegou às mãos do Presidente dos Estados Unidos através do banqueiro Alexander

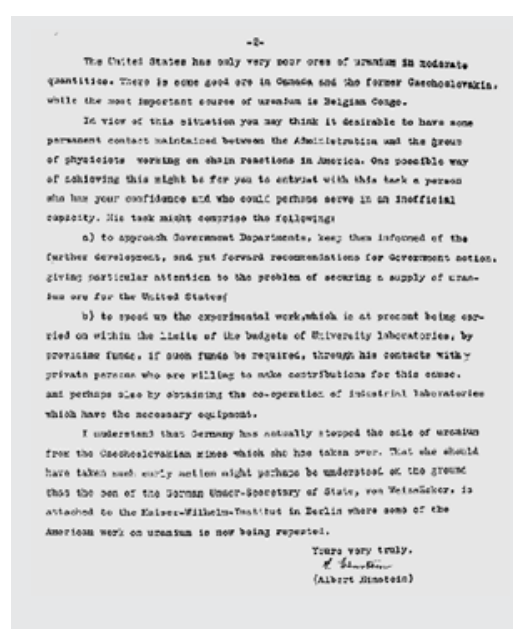

figura 1 Carta de A. Einstein ao Presidente dos EUA, F. D. Roosevelt.

Sachs), a carta que ajudaria a acelerar o Projecto Urânio (figura 1).

O prestígio deste amante da Paz Mundial (por mais irónico que pareça!) pedia "atenção para certos factos e recomendações"; contudo, além desta etapa inicial, Einstein não teve qualquer contacto científico no decurso da realização da bomba e, em Março de 1945, quando teve conhecimento do estádio das investigações realizadas em Los Alamos, escreve ao mesmo Presidente alertando-o em nome da comunidade científica que "não era indispensável nem necessária a utilização da bomba". Contudo, estava lançada a primeira pedra para o apocalipse próximo que daria ao niilismo do Século XX uma solidez sombria, que desencadearia o falhanço na fé dos valores humanos e a desintegração das relações ciência-sociedade, que abalaria a fé inocente na ciência e na humanidade. Desde essa altura, cessou por completo a noção de que os civis deixavam os dissabores e atrocidades da guerra aos soldados e militares; daí em diante, mais do que nunca, o cientista não se pode alhear da sua participação de responsabilidade pelo destino da sociedade e alienar-se dos problemas que transcendem a sua competência científica especializada. Hoje, o cientista tem obrigatoriamente de estar cada vez mais consciente do imperativo de um respeito moral, de uma ciência livre e de uma sociedade justa.

Verdadeiro dilema para estes exploradores da matéria; a matéria que os alquimistas tinham simbolizado como o feminino (a palavra matéria tem a mesma raiz arcaica de mater que significa mãe) era "violada", respondendo logo de modo terrífico. A sua potencialidade destrutiva, os receios de que a nova arma caísse primeiramente nas poderosas mãos de um demoníaco activou o desafio único de lidar com o fenómeno nuclear à grande escala, de congregar esforços de uma comunidade de cientistas nos seus anos mais produtivos e vigorosos. Estava assim lançada a semente de uma unidade social não muito usual em termos de criatividade. Até à década de quarenta, as grandes revoluções científicas estavam centralizadas em redor de figuras proeminentes (caso da primeira década, em torno de cientistas como Einstein, Planck, Rutherford ou Thomson) ou em algumas escolas de investigação (caso da Escola de Copenhaga e as dos mandarins germânicos: Born e Sommerfeld); agora iniciava-se o período da Big Scien$c e$, que albergava centenas de cientistas; algo que era possível porque havia um objectivo comum - um desafio científico e tecnológico que alicia os mais criativos - e um enorme financiamento ${ }^{7}$ - que permitiu não só a mobilidade humana como a aquisição de materiais e instrumentos necessários à realização do projecto. O sucesso espectacular do Laboratório de Los Alamos ${ }^{8}$ foi tão grande que incentivou a construção ou reconversão de instituições científicas em grandes laboratórios como são demonstrativos os casos de Argonne (sul de Chicago), Oak Ridge, Brookhaven National Laboratory, The Radiation Laboratory (Berkeley), CERN, etc.

Resta ainda um ponto a salientar: desde a realização da experiência da primeira 
reacção nuclear em cadeia até à experimentação da primeira bomba atómica, os programas nucleares levaram sensivelmente dois anos e meio - a diferença entre os programas soviético e americano, embora diferindo no tempo ${ }^{9}$, é apenas de 18 dias (é de notar porém que o programa soviético beneficiou do serviço de espionagem $\mathrm{m}^{10}$ ) - o que por si só constitui uma das maiores façanhas da história científica. É difícil imaginar que em tão pequeno período de tempo se conseguissem ultrapassar as dificuldades teóricas e tecnológicas inerentes ao projecto - para não falar dos problemas de organização, administração, regulamentação de segurança e sigilo e relações com o Exército. A máxima a ser cumprida e respeitada era: "When in doubt, act". Estes anos constituíram, sem dúvida, dias de grande avanço para a Física, épocas heróicas para a ciência; mas constituíram igualmente dias de reflexão e de angústia face às implicações da energia atómica: evitar a destruição e a corrida às armas atómicas.

A 16 de Julho de 1945, é testada a primeira bomba atómica em Alamogordo. Otto Frisch que assistia à experiência relata-nos:

«... E, de repente, sem qualquer ruído, um "sol" estava a brilhar. As encostas da areia na orla do deserto lançavam reflexos de uma luz quase sem cor e sem forma. Esta luz parecia não variar durante alguns segundos, e, posteriormente, começou a esbater-se. Voltei-me, mas o objecto no horizonte que parecia um pequeno Sol estava ainda demasiado luminescente para poder olhar para ele. Continuei a piscar os olhos para conseguir ver alguma coisa; passados mais ou menos dez segundos, tal objecto cresceu parecendo-se a um fogo com forma de morango. Lentamente elevavase no céu, mas não se despegava do chão: continuava ligado a ele como se fosse um caule de pó em perfeito turbiIhão. A única imagem que me ocorreu foi a de um elefante vermelho a baloiçar a tromba. Então, à medida que a nuvem de gás quente arrefecia e se tornava menos vermelha, via-se uma chama azul circundante, um clarão de ar ionizado... Era um espectáculo terrível; quem alguma vez presenceia uma ex- plosão atómica nunca mais a esquecerá. E tudo em silêncio absoluto; a detonação veio minutos depois, bastante forte. Embora tapasse os ouvidos, ouvia um ruído prolongado semelhante ao das horas de ponta, mas muito distante. Ainda hoje o posso ouvir. Finalmente, algumas pessoas riram, outras gritaram, a maioria, porém, ficou silenciosa».

Silencioso estava J. Robert Oppenheimer, o mentor do projecto. Quando William L. Laurence, o repórter do New York Times, expressamente autorizado para assistir à experiência, Ihe perguntou o que sentia nesse momento, Oppenheimer, lembrando-se de uma citação do Bhagavad-Gita, afirmou-Ihe: I am become death, the Shatterer of Worlds "eu sou a morte, o destruidor dos mundos". Eis aqui o exemplo do verdadeiro actor, o actor que interage com outros protagonistas e antagonistas, que procura tornar-se consciente a nível moral daquilo que faz e das suas consequências. $\mathrm{O}$ actor é um ser que colide constantemente no drama dos seus limites e suas limitações. Oppenheimer entende, com esta observação, que o seu agir, o seu actuar acarreta intrinsecamente um coagir, ou seja, torna realidade a morte.

Nesse momento, talvez, sem o saber, adivinhava a sequência dos acontecimentos: o lançamento da bomba Little Boy em Hiroxima a 6 de Agosto e Fat Man em Nagasáqui a 9 de Agosto; sem o saber nesse momento, já que, por sua insistência, a Comissão de Energia Atómica havia recomendado a 10 de Maio que antes de qualquer lançamento da bomba, se deviam utilizar os efeitos psicológicos que induzissem o Japão à capitulação e que deveriam ser dadas provas do poder devastador das armas atómicas, de modo a que todas as nações sentissem a necessidade de uma cooperação internacional. Os cientistas alarmados fizeram um esforço enorme para influenciar o curso dos acontecimentos: Leo Szilard, um dos mentores da mencionada carta de Einstein enviada a Roosevelt, preparou uma petição endereçada ao Presidente Truman, uma petição assinada por 67 cientistas de Los Alamos, que apelava à não utilização da bomba, a menos que o Japão fosse previamente avisado e persistisse em resistir à rendição. O General Groves (o Responsável militar do projecto) permitiu uma circulação limitada desta petição, que chegou à Casa Branca deliberadamente após a partida do Presidente para a Conferência Postdam.

Aviso tardio é certo, pois as decisões políticas já estavam tomadas.

Iniciavam-se os tempos da Idade da Ansiedade no dizer de W. H. Auden, da perda da dignidade humana, da condenação de uma arma numa base moral e ética, algo a que os cientistas não foram alheios $^{12}$.

Após o lançamento das bombas atómicas, na carta (17 de Agosto de 1945) que Oppenheimer enviou ao então Secretário da Guerra, Henry Stimson, um documento que tinha o apoio tácito da Association of Los Alamos Scientists (ALAS), afirmava ${ }^{13}$ :

"No futuro próximo, o desenvolvimento de armas atómicas cada vez mais potentes poderá parecer o passo mais natural de qualquer política nacional que pretenda manter as forças militares no seu máximo poder de acção. Contudo, temos grandes dúvidas que um tal desenvolvimento possa contribuir essencial ou permanentemente para a prevenção da guerra. Acreditamos firmemente que a vitalidade e segurança desta Nação - em oposição à sua capacidade de infligir derrotas aos seus inimigos poderosos - não pode basear-se em todo ou no essencial nas proezas técnicas e científicas, mas sim em tornar as guerras impossíveis no futuro. Assim, é nossa recomendação unânime e urgente que, apesar das explorações incompletas das possibilidades técnicas nesta área científica, todos os passos a serem tomados, todos os acordos internacionais a serem efectuados, terão de cumprir este objectivo".

Einstein, essa figura carismática, vai ainda mais longe anunciando que é "impensável que se possa alcançar a paz sem a presença de uma organização genuinamente supranacional que governe as relações internacionais".

Como estas palavras contrastam com as eufóricas alocuções do Presidente Truman, após o lançamento das bombas: 
"O que fizemos foi o maior acontecimento histórico da ciência organizada. Foi feito sob elevada pressão e sem falhanço. Gastámos 2 mil milhões de dólares no maior jogo científico existente até esta data - e ganhámos".

A recusa de muitos cientistas participarem nos programas nucleares subsequentes com objectivo de construção das designadas super-bombas bem como apoiarem movimentos pacifistas ou propostas de controlo da energia atómica ${ }^{14}$ por agências internacionais, causaram-Ihes muitos dissabores. Veja-se, por exemplo, o que aconteceu a Oppenheimer que, após a carta dirigida ao director do FBI, J. Edgar Hoover, por William Borden ${ }^{15}$ (7 NOV 1953), se viu privado do acesso à informação considerada secreta, após prolongadas audições perante a Comissão de Energia Atómica e, ainda o caso de Kapitza, o cientista de maior prestígio da Academia Soviética das Ciências, que, recusandose a trabalhar na bomba, foi preso ou mantido em residência vigiada até à morte de Estaline ${ }^{16}$. Mais recentemente temos o caso de Andrei Sakharov.

As notícias de Hiroxima provocaram a bipolaridade da esperança e do medo. Quando Oppenheimer resignou do cargo de Director de Los Alamos em Agosto de 1946, e decidiu regressar de novo à vida académica aceitando um lugar de Professor no Instituto de Tecnologia da Califórnia, ao receber o Certificate of Appreciation dado pelo Governo dos Estados Unidos, refere-se implicitamente a essa bipolaridade: "É nossa esperança que no futuro se possa olhar para este Certificado, e para tudo o que ele significa, com orgulho. Hoje, esse orgulho tem de ser atenuado com uma profunda preocupação. Se as bombas atómicas forem consideradas como novas armas dos arsenais de países hostis ou de arsenais de nações que se preparam para a guerra, então haverá um tempo em que a humanidade amaldiçoará os nomes de Los Alamos e Hiroxima".

Ainda hoje balançamos entre esses dois pólos, entre a desconfiança irremediável conducente a um apocalipse e a utilização da energia atómica que se identifique com a ideia de progresso e bem-estar de uma civilização moderna.

\section{Requiem Para o Novo Levantar Solar}

Às oito e quinze, segunda-feira, na manhã do dia 6 de Agosto de 1945 Edith Sitwell

Transfixa estou ao meu coração como Ixião à sua roda,

Pregada a meu coração como o Ladrão à Cruz,

Suspendo-me entre o Cristo nosso e o abismo por onde o mundo [se perdeu

E vejo o Sol-espectro na Via Faminta,

- O espectro do coração do Homem ... Caim vermelho

E o cérebro mais assassino

Do Homem, e Nero, mais vermelho ainda, que concebeu a morte

Da sua madre Terra, rasgou

O seu ventre, para descobrir o lugar onde ele fora concebido.

Mas nenhum olho escureceu -

Nenhum olhar resta que estremeça:

Olhos cegados como os anos

Desde que nasceu Cristo. Mãe ou Assassino, haveis [ora arrebatado, ora dado a vida -

Hoje não há diferença!

Houvera antanho uma manhã quando a Luz sagrada Alvorecia. A bela Primeira Criatura aproximava-se

À nossa fonte, e achou-nos sem mácula.

Os nossos corações pareciam seguros no peito e cantavam à

Luz-

A polpa dos nossos ossos

Julgávamos segura... o sangue nas veias, a seiva [na árvore

Eram mananciais da Deidade.

Vi então os pequenos homens-Formigas a precipitarem-se Carregando o peso da mácula do mundo (tão pesada como o mundo) E a mácula no coração do Homem

Cada vez mais compacta até que a avareza e a cupidez [atingiram um calor [maior que o do Sol.

E o raio emitido por aquele calor aproximava-se silente, sacudiu [o céu

Como se em busca de alimento, e comprimiu os troncos

De tudo o que cresce na terra até secarem

- E sugou a polpa aos nossos ossos:

Os olhos que viam, os lábios Que beijavam: já são abolidos

Ou negros qual um obscuro trovoar se prostram mostrando o seu [ricto ao Sol assassinado.

Os vivos que já não podem ver e os Mortos Que vêem juntos [se deitam

Como se unidos pelo amor... Cessou então o ódio;

Cessou então o amor: Extinto está o coração do Homem.

(Tradução de Christopher Auretta) 
O redespertar do medo da guerra e os riscos que envolvem a energia nuclear não devem ser descurados em momentos de decisão tomados pela sociedade; a aquisição de armas nucleares e a corrida ao armamento devem ser denunciados e discutidos não só pela comunidade científica como também pelo cidadão-comum.

Até que ponto, poder-se-á perguntar, os instrumentos, as teorias, as operações mentais, as atitudes racionais face à criação, e, em última análise, a aquisição do conhecimento, acarretam também a destruição ou sentido de destruição?

Edith Sitwell, por exemplo, no prodigioso poema Dirge for the New Sunrise, escrito na segunda-feira fatídica de 6 de Agosto de 1945 (ver caixa) regista o que o mero observador esquece: a natureza conservar-se-á apenas quando o saber do Homem obriga o observador a sentir os rigores (o poema alude a uma crucificação colectiva) do seu protagonismo intrínseco e ambíguo: criador ou assassino?

Tem-se por vezes a ideia que o trabalho científico é efectuado em torres laboratoriais de marfim, impunes às pressões, influências e intromissões do mundo exterior, e que os cientistas, obcecados pelo desbravar do conhecimento, agem como se fossem verdadeiros magos em busca dos eternos polifacéticos segredos da natureza, ignorando os problemas mundanos.

Esta imagem, imposta pelo poder do cientismo, pode seduzir facilmente o ini-

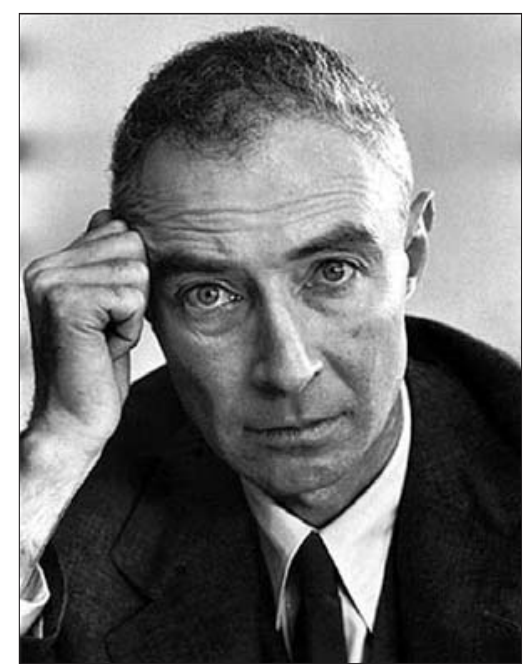

figura 2 J. Robert Oppenheimer (1904-1967)
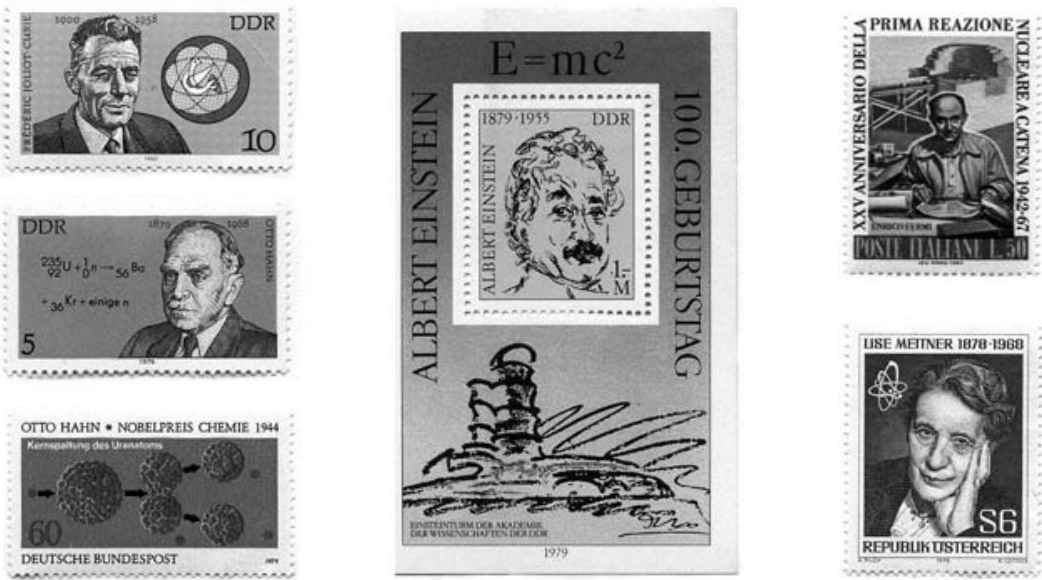

figura 3 Emissões filatélicas retratando alguns dos cientistas mencionados no texto: A. Einstein (1879-1955), Frederic Joliot-Curie (1900-1958), Otto Hahn (1879-1968) e a fissão nuclear do átomo de Urânio, Fermi (1901-1954) e Lise Meitner (1878-1968).

ciado, que, aparentemente, se encontra disponível para devotar a vida inteira à busca do conhecimento per si. Muitas vezes, os cientistas limitam-se a transportar para o estado adulto a sua curiosidade, o poder argumentativo e a rebeldia tão característicos do período juvenil, e tentam assim desbravar o "desconhecido", com ou sem companheiros de aventura. Contudo, se apenas este desafio intelectual constituir o seu único universo, o seu único objectivo, os cientistas poderão ser certamente observadores perspicazes e, embora possam contribuir para o progresso científico, na verdade, encontram-se demasiadamente empobrecidos. Não se deve esquecer que a decifração da natureza e a escrita da alma formam uma única linguagem, um singular idioma, um só tecido. Se o cientista conseguir alcançar essa unidade, então torna-se em verdadeiro actor, no sentido mais profundo: torna-se não só um contribuinte para o progresso da ciência mas também um árbitro consciente da história da Humanidade.

Uma das personagens da era do nuclear em que se visualiza uma maior interpenetração da dualidade actor/observador é sem dúvida Robert Oppenheimer. Em 1964, três anos antes de morrer, na Reunião de Mount Kisco afirmava o seguinte (e com estas palavras me despeço):

"Até hoje, e possivelmente com maior frequência nos dias da minha infinda prolongada adolescência, qualquer que fosse a minha actuação - bem sucedida ou não -, fosse um artigo de Física, uma aula, uma leitura de um livro, uma conversa com um amigo, como gostei e amei as pessoas, surgiu sempre em mim um grande sentido de mudança e do que é injusto. Para mim, tornou-se impossível viver... humanamente, sem compreender que o que eu via era somente uma parte da verdade... e, na tentativa de surgir como, (e de ser) um homem racional, tive de perceber que as minhas preocupações eram válidas e importantes, mas não eram a história completa; havia igualmente um outro olhar complementar, porque outras pessoas as divisavam de modo diferente. E tive de sentir, que, para elas, tais critérios satisfaziam também as suas necessidades".

\section{Notas}

${ }^{1}$ À experiência assistiram 43 pessoas: Enrico Fermi, H. M. Agnew, S.K. Allison, H.L. Anderson, W. Arnold, H. M. Barton Jr. T. Brill, R. F. Christy, A. H. Compton, R. J. Fox, S. A. Fox, D. K. Froman, A. C. Graves, C. H. Greenewalt, N.Hilberry, D. L. Hill, W. H. Hinch, W. R. Kanne, P. G. Koontz, H. E. Kubitschek, H. V. Lichtenburger, G. Miller, G. Monk Jr., R. G. Nobles, W. E. Nyer, W. P. Overbeck, H. J. Parsons, G. S. Pawlicki, L. Sayvetz, L. Seren, L. A. Slotin, F. H. Spedding, W. J. Sturm, L. Szilard, A. Wattenburg, R. J. Watts, G. L. Weil, E. P. Wigner, M. Wilkening, V. C. Wilson, E. O. Wollan, L. Woods, W. H. Zinn.

${ }^{2}$ É interessante ver que, em 1973, Andrei Sakharov e mais dois colegas enviaram um memorandum a Leonid Brezhnev indicando que o atraso científico soviético se devia à in- 
suficiência de Instituições democráticas governamentais e à falta de liberdade intelectual e permuta livre de informação entre os cientistas.

${ }^{3}$ Por vezes o cientista pode dissimular os seus conhecimentos ou até escondê-los quando pretende a prioridade da descoberta de algo que está a investigar. Contudo logo que conclui a sua missão, gosta de partilhar e divulgar o "novo" conhecimento. No contexto aqui mencionado, a circulação da informação para o exterior é completamente vedada.

${ }^{4}$ Era difícil aceitar que os produtos do bombardeamento do urânio pelos neutrões não fossem elementos semelhantes ao urânio os transuranianos. Essa era a tradição teórica vigente e, consequentemente, fazia parte do treino dos físicos que a aceitavam sem crítica. Assim, não é de admirar que Hahn e Strassmann no referido artigo referissem que como químicos teriam de concluir com relutância que os isótopos hipotéticos de Rádio eram de facto bário, mas que como físicos nucleares não podiam considerar esta hipótese senão como um facto dramático por si só, já que ela era contrária a todas as experiências nucleares anteriores. 0 fenómeno da cisão nuclear foi explicado por Lise Meitner e Otto Frisch (Lise Meitner já se encontrava a viver na Suécia) e foi divulgado por Niels Bohr na 5th Annual Conference on Theoretical Physics, em Washington D.C. (26-28 Janeiro de 1939). 0 impacto desta notícia junto da comunidade científica foi tão grande que, em 1939, publicaram-se 104 artigos provenientes de 12 países com base neste fenómeno, contrariamente ao que acontecera em anos anteriores.

${ }^{5} \mathrm{O}$ programa nuclear soviético teve início em 1943, sob orientação de Igor Kurchatov depois de G. N. Flerov, após consulta à literatura estrangeira, escrever à Comissão de Defesa: "não há tempo a perder para se iniciar a construção da bomba de urânio". O governo pediu a Peter L. Kapitza e Abram Joffe opinião sobre o assunto e constituiu-se o grupo de investigação que incluía além do orientador os seguintes físicos: I. K. Kiloin, Ya, B. Zeldovitch, A. I. Alikhanov, G. N. Flerov, Yu. Ya. Pomeranchuk, B. V. Kurchatov (irmão de Igor), I. I. Gurevich, G. Ya. Schchepkin, Yu. B. Khariton, M. S. Kozodaev, V. P. Dzhelov, L. M. Nemerov, V. A. Davidendov. Ver in Herbert F. York, The Advisor - Oppenheimer, Tel- ler and the Superbomb, W. H. Freeman and Co, 1976, p. 29.

${ }^{6}$ É interessante notar que tal abalo é ainda hoje presente: Recentemente um psicólogo francês pedia num inquérito respostas imediatas à palavra "átomo". Apenas um pequeno número de pessoas respondeu com as palavras progresso ou futuro; a maioria mencionava: Hiroxima, desastre, morte.

${ }^{7}$ Durante a guerra, o investimento federal dos Estados Unidos na investigação cientifica passou de $18 \%$ a $83 \%$ das Despesas Públicas e Privadas (de cerca de $\$ 48 \times 10^{6}$ a $\$ 500 \times 10^{6}$ ) in Science and Public Policy: a report to the President, 1947. Além disso, o empenhamento do Estado em qualquer projecto pode rodear barreiras burocráticas e técnicas impensáveis. Por exemplo, neste projecto foram pedidas ao Tesouro Americano - e cedidas (!) - toneladas de prata (o cobre encontrava-se esgotado) para serem utilizados em bobinas dos enormes imanes do calutrão, um instrumento necessário à separação do urânio.

${ }^{8} \mathrm{O}$ Laboratório que inicialmente empregava 100 pessoas, em menos de seis meses atingia um total de 3000. O Laboratório estava dividido em 4 Divisões: A Divisão de Física Teórica sob chefia de Hans Bethe; a Divisão de Física Experimental sob orientação de Robert Bacher; a Divisão de Química e Metalurgia sob a supervisão de Joseph W. Kennedy (um jovem de 26 anos) e a Divisão de Material Militar sob o Comando do Capitão William (Deke) Parsons.

${ }^{9} \mathrm{O}$ período americano vai de 2 de Dezembro de 1942 (1. ${ }^{a}$ reacção nuclear em cadeia, Chicago) a 16 Julho de 1945 (experiência Trinity em Alamogordo) e o soviético entre 25 de Dezembro de 1946 e 19 de Agosto de 1949.

${ }^{10}$ Em 1950, descobriu-se que Klaus Fuchs, membro do grupo Britânico de Los Alamos era espião a favor da União Soviética. A "paranóia" da espionagem científica aliada à Segurança do Estado levaram a que Robert Oppenheimer, o responsável do projecto de Manhattan (que no dizer que Robert Serber "Los Alamos poderia ter alcançado êxito sem ele [Oppenheimer] mas certamente somente com uma maior tensão, menos entusiasmo e mais lentidão"), fosse inquirido e sujeito a audiências em 1954, de modo a testemunhar a sua idoneidade e conservar $\mathrm{o}$ acesso a toda a informação secreta, que acabaria por perdê-lo nesse mesmo ano.
${ }^{11}$ Shervin, Martin J., A World Destroyed: The Atomic Bomb and the Grand Alliance, Alfred A. Knopf, 1975, p. 229-230.

${ }^{12}$ Não deixa de ser curioso notar toda uma carga política utilizada na descrição do teste da bomba atómica soviética realizada a 28 de Agosto de 1949 na presença das altas chefias militares e governamentais, uma bomba denominada Joe / pelos americanos: "Quando os físicos que criaram a bomba viram o flash brilhante, mais brilhante que o Sol, e a nuvem em forma de cogumelo subir na atmosfera, deram um sinal de alívio. Tinham realizado os seus deveres. Ninguém sentiu medo como no caso dos físicos americanos que a esconderam e que fabricaram uma arma para o exército de um país que, para a maioria deles, não era o seu, e cujo governo a utilizou contra as populações pacíficas de Hiroxima e Nagasáqui.

Os físicos soviéticos sabiam que criaram a arma para o seu próprio povo e exército que defendia a paz. O seu trabalho, as noites sem dormir e o enorme esforço dispendido durante os últimos anos não tinham sido em vão: tinham retirado o trunfo das mãos dos diplomatas americanos".

${ }^{13}$ Robert Oppenheimer - Letters and Recollections, Harvard University Press, 1980, p. 294.

${ }^{14}$ Caso dos Relatórios Acheson-Lilienthal (Oppenheimer estava por trás do relatório que indicava que o controlo internacional da energia atómica implicava a anulação do monopólio dessa energia por qualquer país para salvaguarda das nações) e dos movimentos Pugwash.

${ }^{15} \mathrm{O}$ propósito desta carta - escrevia William Borden - é afirmar a minha convicção, baseada em anos de estudos de documentos disponiveis ainda sob sigilo que, mais provavelmente do que não, J. Robert Oppenheimer é um agente da União Soviética" in USAEC, In the Matter of J. Robert Oppenheimer, MIT Press, p. 837.

${ }^{16}$ Curiosamente ambos os cientistas seriam reabilitados posteriormente: Kapitza receberia pela segunda vez a Medalha de Herói dos Trabalhadores Socialistas em 1974, aquando do $80{ }^{\circ}$ aniversário do seu nascimento, e, Oppenheimer receberia, em 1963, o Prémio Enrico Fermi dado pelo Presidente Johnson. 


\section{Inn livro teórico para as aulas práticas}

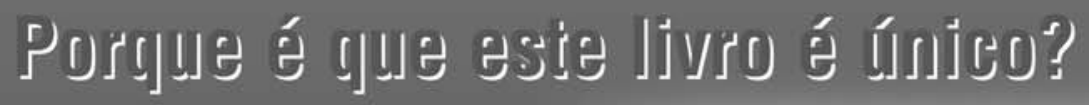

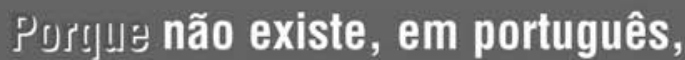
mais nenhuma obra que trate das regras gerais de "comportamento" num laboratório

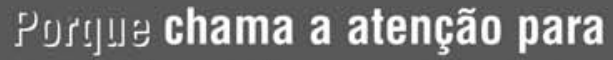
o problema da segurança nos laboratórios

Pอร!] de tópicos essenciais que, por falta de tempo, raramente são tratados nas aulas com um nível adequado:

- Elaboração de relatórios

- Pesquisa bibliográfica

- Aquisição automática de dados

- Análise e tratamento de dados experimentais

- Apresentação de dados em gráficos e medida de algumas propriedades

\section{GUIA DO LABORATÓRIO DE QUÍMICA E BIOQUÍMICA}

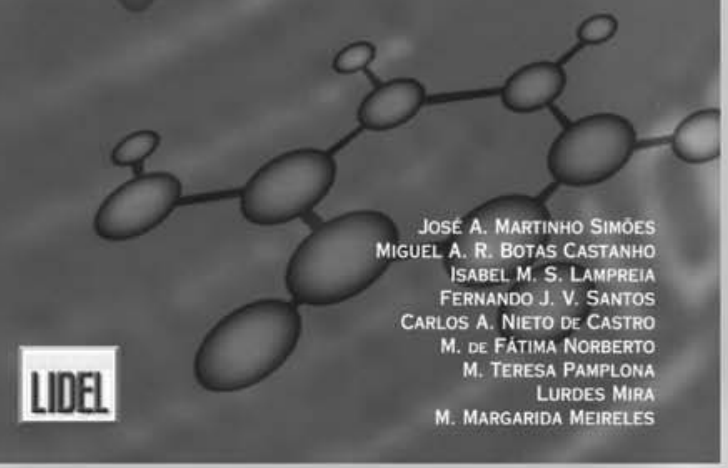

D: Direjios de Autor desia vida revertem a favor da

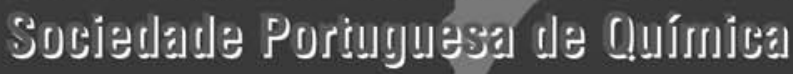

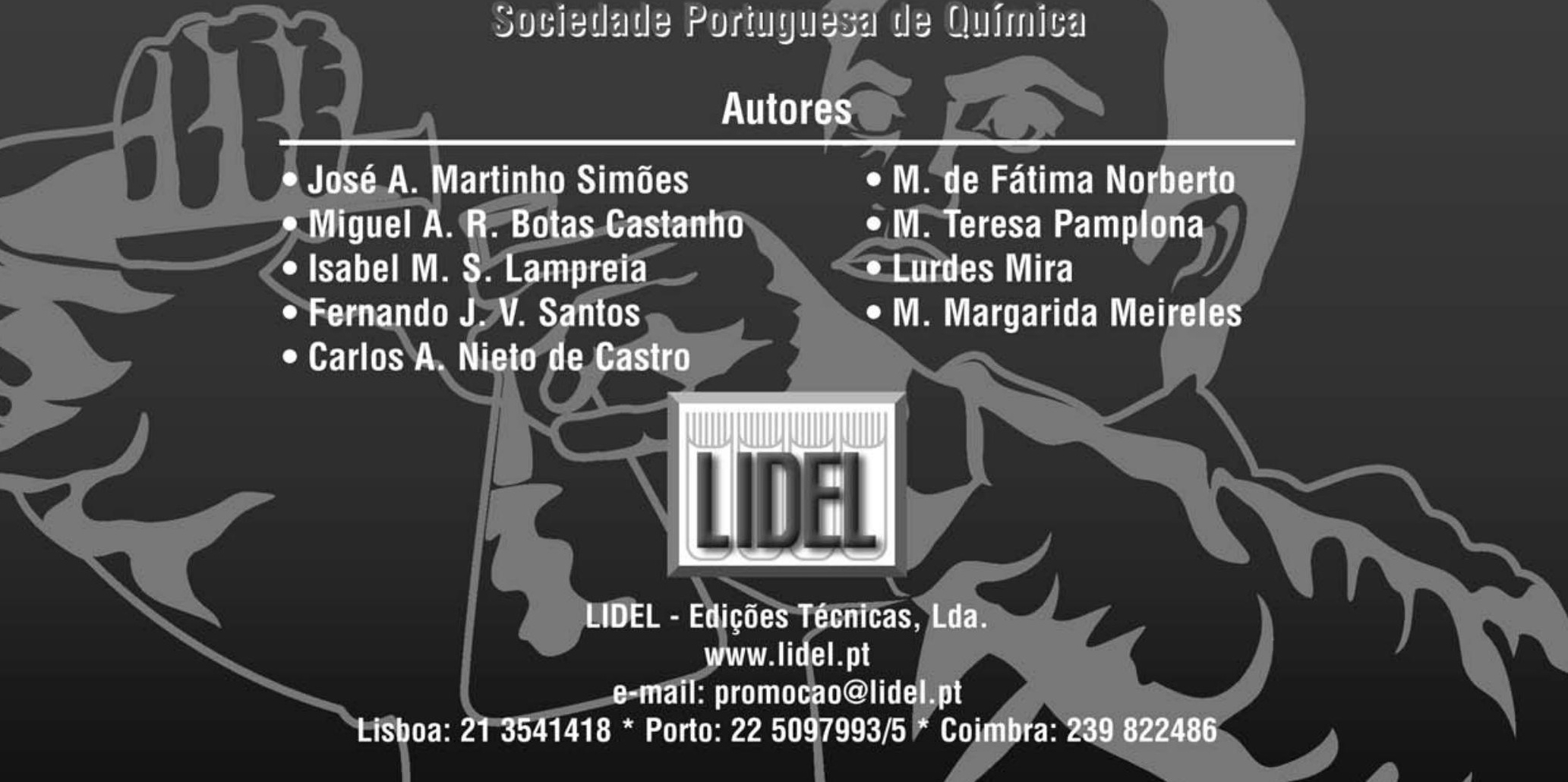

